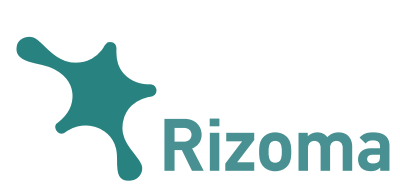

\title{
Apocalipse When?
}

\section{Futuros distópicos nos seriados contemporâneos de ficção científica de televisão}

\begin{abstract}
Resumo: Este texto busca refletir sobre obras de ficção científica, especificamente os seriados de televisão contemporâneos, como formas de mediação da nossa realidade e de nossas expectativas para o futuro. A partir de uma breve revisão bibliográfica e documental, o trabalho, de caráter exploratório, pensa sobre a importância destes seriados frente à urgência dos medos e desesperanças quanto à imprevisibilidade do que está por vir, principalmente nas novas gerações, em um contexto de crises políticas, econômicas e sociais. Entende-se que estas histórias de ficção distópicas apelam para os espectadores, pois dão vida nas telas para a imaginação e trazem conforto ao possibilitarem que estes vivam, lidem e enfrentem, através de personagens, suas ansiedades, medos e angústias em relação ao futuro.
\end{abstract}

Palavras-chave: Futuro. Apocalipse. Ficção científica. Seriado.

\section{Apocalipse When? Futuros distópicos en las series contemporáneas de ciencia ficción de televisión}

Resumen: Este texto busca reflexionar sobre obras de ciencia ficción, específicamente las series de televisión contemporáneas, como formas de mediación de nuestra realidad y de nuestras expectativas para el futuro. A partir de una breve revisión bibliográfica y documental, el trabajo, de carácter exploratorio, piensa sobre la importancia de estos seriados frente a la urgencia de los miedos y desesperanzas en cuanto a la imprevisibilidad de lo que está por venir, principalmente en las nuevas generaciones, en un contexto de crisis políticas económicas y sociales. Se entiende que estas historias de ficción distópicas apelan a los espectadores, pues dan vida en las pantallas a la imaginación y traen confort al posibilitar que éstos vivan, tratan y enfrenten, a través de personajes, sus ansiedades, miedos y angustias en relación al futuro.

Palabras-clave: Futuro. Apocalipse. Ciencia ficción. Serie.

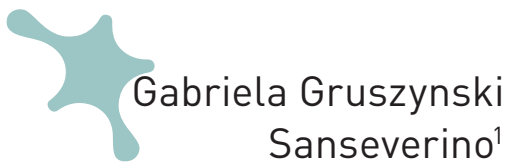

${ }^{1}$ Doutoranda em Estudos de Comunicação: Tecnologia, Cultura e Sociedade - FCT, Lisboa, Portugal. Mestre em Comunicação e Informação pela Universidade Federal do Rio Grande do Sul (UFRGS). Graduada em

Comunicação Social/Jornalismo pela Faculdade de Biblioteconomia e Comunicação (Fabico) da Universidade Federal do Rio Grande do Sul (UFRGS). 


\title{
YRizoma
}

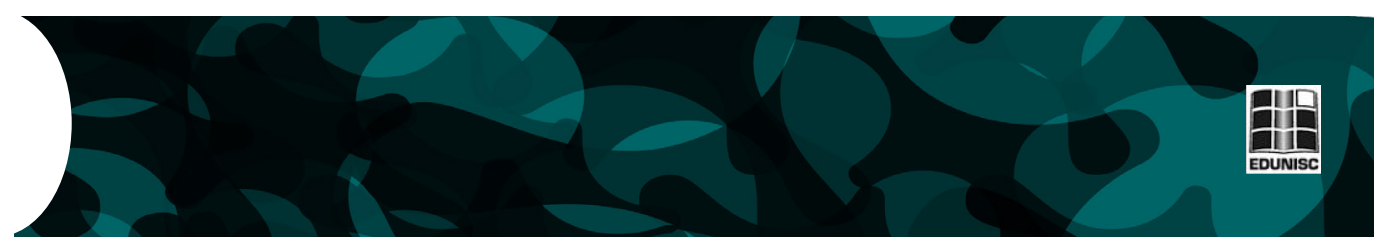

\section{Apocalypse When? Distopical futures in contemporary Science Fiction television shows}

\begin{abstract}
This text seeks to reflect on works of Science Fiction, specifically contemporary television series, as ways of mediating our reality and our expectations for the future. From a brief bibliographical and documental review, this exploratory work thinks about the importance of these serial narratives in a context where there's urgency in our fears and hopelessness as to the unpredictability of what is to come, especially in the new generations, in a context of political, economic and social crisis. It is understood that these dystopian fiction stories appeal to viewers because they give life in the screen for the imagination and bring comfort by allowing spectators to live, deal with and face through fictional characters, their anxieties, fears and anguish about the future.
\end{abstract}

Keywords: Future. Apocalypse. Science Fiction. TV show.

Aliens, zumbis, vampiros? Eles ainda brigam nas telas para decidir qual será responsável pela destruição da raça humana, mas, nos seriados de ficção científica, que têm se tornado mais plurais e mais populares, dão vida a um futuro parco para a humanidade. Enquanto podem ser irrealistas no sentido de que não mimetizam nosso cotidiano e não correspondem ao que racionalmente sabemos sobre o mundo, eles se configuram como expressões não apenas da imaginação e da criatividade de seus produtores, mas de uma desesperança sintomática em relação ao nosso futuro.

Nas sociedades tradicionais, o mito era tido como referência das experiências do mundo, como forma de pensar as dualidades da realidade humana - morte e vida, bem e mal (MOTTA, 2003): um parâmetro comum para a integração da comunidade que oferecia explicações para os acontecimentos enfrentados diariamente, partilhados por todos. Com a época moderna, contudo, o saber mítico passou a ser visto como um entrave para o conhecimento, e a sociedade perdeu aquilo que utilizava para organizar e dar coerência aos acontecimentos do mundo.

Os estereótipos criados por cada cultura, que auxiliam na interpretação do mundo, antes repassados pelos mitos, passam a ser reproduzidos por outros espaços, como os meios de comunicação (RODRIGUES, 1993). Na época moderna, encontram-se, então, nas notícias, no cinema, na literatura, na televisão, maneiras de se organizar a experiência do acaso e lhe dar racionalidade, preenchendo o espaço antes ocupado pelo mito.

Em nossa busca por interpretar o cotidiano, criamos formas cada vez mais elaboradas de dar sentido ao caos da realidade a nossa volta. Os seriados de televisão, criando mundos imaginários, construíram universos que refletiam visões únicas do cotidiano, que possibilitaram que os sujeitos, em contato com os programas, acionassem estratégias próprias para interpretar a realidade em que vivem. As narrativas, assim, criam imagens 
e representações do dia a dia das pessoas, que as observam e as absorvem como forma de pensarem aquilo que está presente em suas vidas.

Os seres humanos possuem o domínio científico e tecnológico que, em teoria, nos permitiria moldar o nosso futuro de acordo com nossas necessidades e desejos. As últimas décadas, entretanto, marcadas por crises políticas, econômicas e sociais, evidenciam a aterrorizante imprevisibilidade do nosso futuro - estaria a raça humana enfrentando a ameaça de extinção? $\mathrm{O}$ aumento brusco nos conflitos armados nos últimos anos está superando nossa capacidade de lidar com as suas consequências; a crise global dos refugiados; a propagação do terrorismo; a nossa incapacidade coletiva de resolver desordens no âmbito mundial está a dar origem a novas ameaças e emergências em um contexto de medo que ultrapassa a realidade e chega às telas de televisão.

Não é de se admirar que ficção científica se tornou uma parte intrínseca da imaginação, com histórias criadas a partir de diferentes formas de expressão cultural, como livros, filmes e histórias em quadrinho. Se as narrativas apocalípticas já haviam explodido no cinema com imagens de catástrofe em todas as formas, os seriados de televisão se tornaram uma nova maneira de expressar os imaginativos fins da raça humana. A televisão acumulou, em sua história, um amplo e denso repertório de obras criativas que permite considerá-la como um dos fenômenos culturais mais importantes do nosso tempo (MACHADO, 2000) e tornou-se uma parte intrínseca do cotidiano.

Um dos produtos ficcionais televisivos de maior circulação são os seriados, em que há um domínio de mercado pelas produções norte-americanas. Os seriados de televisão se tornam uma forma de mediação da realidade e encontram seu sucesso não devido aos seus procedimentos visuais, retóricos e narrativos, mas pelo ganho simbólico que proporcionam ao espectador.

A ficção científica passa a assumir uma função que ultrapassa o entreter e assume um propósito importante: ao nos envolver no ato de imaginar o desconhecido, ela nos prepara para o futuro e auxilia a lidar com a realidade a nossa frente. Mesmo nos cenários que diríamos ser irrealistas, nas histórias em que o apocalipse chega por aliens, zumbis ou vampiros, encontramos um espaço de mediação para os conflitos latentes na sociedade, em um momento em que a nossa civilização parece estar no extremo de duas potencialidades - de florescer ou se deteriorar, de encontrar um futuro pacífico ou tornar-se extinta.

Este texto busca, a partir de uma breve revisão bibliográfica e documental, refletir sobre as obras de ficção científica, especificamente os seriados de televisão contemporâneos, como formas de mediação da nossa realidade e de nossas expectativas para o futuro. Inicialmente, propomos um olhar sobre o desenvolvimento do formato de ficção científica e sua chegada à televisão e definimos o que entendemos como seriados de ficção. Posteriormente, em um texto de caráter exploratório, que busca acionar conceitos que nos permitam pensar as séries de ficção científica como maneiras de pensarmos sobre a nossa realidade e, especialmente, o nosso futuro, em um contexto de crises políticas, econômicas e sociais, estabelecemos que estas parecem refletir a urgência dos medos e das desesperanças quanto à imprevisibilidade do que está por vir, principalmente nas novas gerações 


\section{YRizoma}

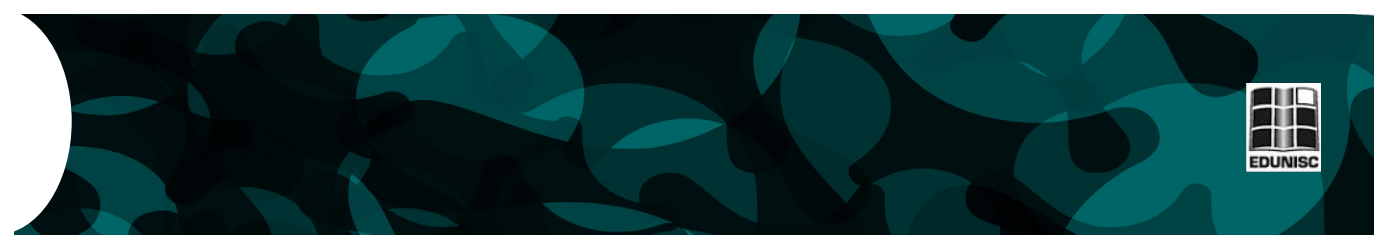

\section{Fiç̧ão científica e a criação de futuros distópicos}

A ficção científica se tornou uma forma comum no contemporâneo de pensar o futuro, popularizada por sua capacidade de ressonar as dimensões fundamentais da preocupação humana com o que está por vir (LOMBARDO, 2006). A ficção científica surgiu pela primeira vez como um gênero popular na década de 1930, quando as pulp magazines, revistas de ficção baratas conhecidas na época, seguiram o exemplo de Hugo Gernsback, criador da publicação Amazing Stories, a primeira revista dedicada exclusivamente ao formato, lançada em 1926. Em 1939, John Campbell evoluiu o que foi proposto por Gernsback e criou Astounding Science Fiction, que se tornou o exemplo paradigmático do que a ficção científica deveria aspirar a ser (FRANKLIN, 1983).

Por trinta anos depois da década de 30 , a ficção científica continuou a ser um gênero baseado em revistas, nas quais os fundamentos econômicos do formato estavam firmemente situados. Depois de 1960, no entanto, o mercado de revistas começou a desaparecer gradualmente, enquanto os editores de livros de bolso se tornaram os principais financiadores da ficção científica. Cerca de trinta anos depois, em 1990, o gênero de ficção científica voltou a aparecer de forma significativa na televisão, primeiro como uma programação de nicho e, posteriormente, alcançando um público mais amplo (STABLEFORD, 1996).

A capacidade da TV como meio narrativo tornou-lhe um ambiente propício para trazer nossas diferentes imagens do futuro para a vida. Os programas de televisão que possuem, em teoria, a possibilidade de uma duração infinita, têm o tempo e os recursos para construir complexos mundos e explorar em profundidade os personagens - a forma de contar para a tela tem uma nova linguagem e um novo ritmo das histórias contadas nos livros e revistas.

\subsection{De que seriados estamos falando}

As séries de televisão baseiam-se em uma estética de repetição: continuação das aventuras, ações e dramas dos personagens e dos recursos utilizados que conseguem proporcionar ao público uma vasta combinação de variáveis temáticas e narrativas. Os seriados dependem da memória do público para se sustentarem, que precisa conseguir acompanhar e entender a história, juntando as informações que lhes são dadas em cada episódio.

Na televisão, como explica Carlos (2006), é possível acumular um grande volume de informações e desenvolvê-las em uma ordem dramática natural. Criam-se, então, narrativas em dois níveis, com a trama principal completa para cada episódio e várias tramas secundárias que serão desenvolvidas ao longo de uma temporada ou mesmo de toda a série. Dessa forma, satisfaz-se a tensão de cada episódio e se mantém o interesse do espectador pela perspectiva de continuidade da história. Os seriados ganham uma complexidade cada vez maior, construídos por uma tapeçaria 
de histórias e de personagens. Os detalhes ganham importância devagar e dentro de padrão repetidos de ação, podendo ser percebidos e compreendidos pelos espectadores.

Para Jost (2012), o crescente interesse pelos seriados passa pela legitimidade que o formato ganhou a partir de produções inovadoras, principalmente a partir dos anos 1980, quando começou a existir maior variedade de programação. O sucesso e a importância cultural das séries estão nas relações que estabelecem com seus espectadores.

Ao pensarmos nas narrativas audiovisuais, como explica Aumont (2002), sempre teremos, por exemplo, "uma mesma história e uma história diferente": há uma base igual para o formato, que ganha uma nova roupagem para proposta de história, mas que ainda permite ao público reconhecer o modelo e tentar prever a continuação e decidir se quer ou não a conhecer. As narrativas vão tornar o natural programado, isto é, o público terá a sensação de uma progressão não garantida, que a história é conduzida pelo acaso e submetida à realidade, mas sabendo que há o desenvolvimento organizado da narrativa.

Dois processos, de acordo com Aumont (2002), permitem ao público conhecer a história, ver nela uma verossimilhança com a sua realidade e ter o conforto de acreditar que pode adivinhar como a narrativa irá se desenvolver. O primeiro é a intriga da predestinação, no qual é apresentado no início da narrativa o essencial para o espectador conhecer a história e pensar em sua provável solução: é dada a orientação da narrativa. O segundo processo é a fase hermenêutica e corresponde ao arsenal de atrasos que os personagens deverão enfrentar antes de chegar à solução da intriga proposta pela narrativa. São o que Aumont (2002) chama de etapas-paradas, isto é, desafios que devem ser superados pelos personagens que conduzem a narrativa do seu enigma até a sua solução.

Mesmo existindo, contudo, uma variação de temas, as séries de televisão se baseiam em uma estética de repetição: continuação das aventuras, ações e dramas dos personagens e dos recursos utilizados que conseguem proporcionar ao público uma vasta combinação de variáveis temáticas e narrativas. Os seriados dependem da memória do público, que precisa conseguir acompanhar e entender a história, juntando as informações que lhes são dadas em cada episódio.

A vivência dos personagens nas telas pode ser identificada com aquelas dos espectadores em seu cotidiano. Um processo de triplo envelhecimento é percebido em um desenvolvimento narrativo único: ator, personagem e espectador crescem, envelhecem e mudam. Os espectadores passaram a conseguir se identificar com os personagens que viam na televisão, pois não era apenas um personagem que os espectadores viam crescer, era um filho que poderia ser seu ou uma pessoa que cada um de nós poderia ser (CARLOS, 2006). Os seriados podem ser percebidos como uma crônica dos tempos atuais, um retrato do cotidiano, espaços em que se pode viver vidas alheias e encontrar nelas significados para a própria vida: "os espectadores encontraram refúgio em assistir $\mathrm{e}$ - de fato se identificar - com os personagens"2 (HELFAND, 2001, p.10, tradução nossa).
${ }^{2}$ No original: "viewers found respite in watching - and indeed identifying with - characters". 


\section{$\gamma_{\text {Rizoma }}$}

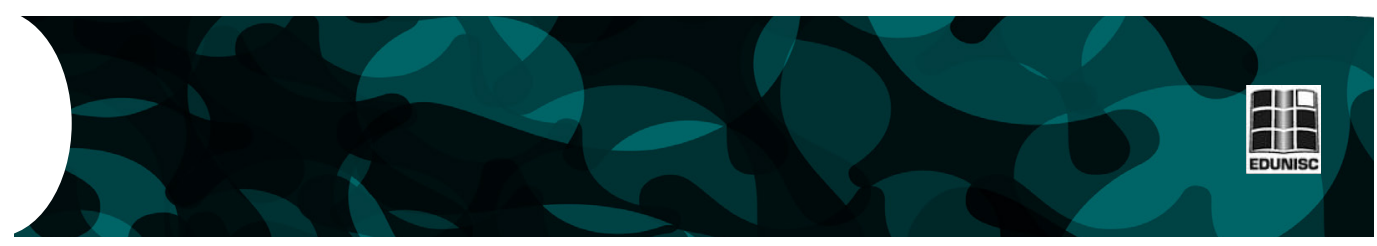

\subsection{Opção: Apocalipse}

A televisão contemporânea tem sido atraída pela ficção científica e pelo desafio de visualizar o inimaginável em um momento em que o recente aumento nos cenários distópicos e pós-apocalípticos parecem mais urgentes e mais extremos. A ficção apocalíptica e pós-apocalíptica é um subgênero de ficção científica, em que a civilização da terra está em colapso ou desabou. $\mathrm{O}$ evento do apocalipse pode ser climático, como mudança climática desenfreada; natural, como um evento de impacto; feito pelo homem, como a guerra nuclear; médico, como uma praga ou vírus, seja natural ou artificial; ou imaginativo, como apocalipse zumbi, invasão alienígena e vampiros.

A história pode envolver tentativas de prevenir um evento apocalíptico, lidar com o impacto e as consequências do próprio evento, ou pode ser pósapocalíptico, definido após o evento. O prazo pode ser imediatamente após a catástrofe, focalizando as dificuldades ou a psicologia dos sobreviventes, a maneira de manter a raça humana viva e junta como uma, ou consideravelmente mais tarde, muitas vezes incluindo o tema que a existência da civilização précatástrofe foi esquecida. As histórias pós-apocalípticas geralmente ocorrem em um mundo futuro não-tecnológico ou em um mundo onde apenas elementos dispersos da sociedade e da tecnologia permanecem.

Nas narrativas de ficção científica, torna-se essencial a existência de uma verossimilhança interna. Enquanto, por exemplo, um mundo tomado por zumbis poderia não fazer qualquer sentindo para o público, já que em nossa realidade teoricamente não existe esta possibilidade. À medida que a TV cria um universo que faz sentido em si mesmo, que respeite sua lógica interna (naquele programa faz sentindo as pessoas conviverem com mortosvivos), os sujeitos conseguem perceber a história como um todo coerente.

Mesmo nos cenários fantásticos, onde o impossível (em nossa realidade) acontece, elementos do cotidiano continuam a compor a história. Têm-se as dicotomias de bem e mal, e mesmo quando elas são questionadas, têm-se heróis e vilões, têm-se sofrimento, romance e vitória. Ao manter a coerência interna, a história garante que, mesmo nas narrativas incríveis, o público consiga encontrar personagens com os quais pode se identificar e situações das quais pode se apropriar para pensar o seu dia a dia.

As histórias, em suas épocas, podem ser percebidas como crônicas de seu tempo corrente, retratos do cotidiano: espaços em que se pode viver vidas alheias e encontrar nelas significados para a própria vida. São um espelho da sociedade em que se inserem, sempre colocadas no contexto da cultura, incorporando grandes e pequenos acontecimentos da realidade social, assumindo a função de oferecer explicações para os episódios que as pessoas enfrentam diariamente.

O seriado V, de 2009, foi lançado em meio à brutal crise econômica mundial e trazia um cenário no qual aliens vêm à Terra sob a suposta intenção de salvá-la, mas logo o objetivo de dominar os humanos é demonstrado. Falling Skies (2011) e Colony (2016), que também têm a chegada dos aliens ao nosso planeta como enredo, acabam sujeitando as mesmas questões: precisamos de 

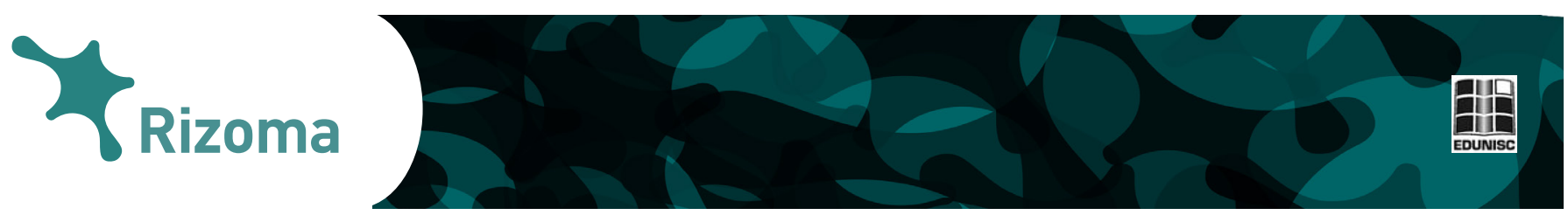

outra raça para salvar nosso futuro? Seria nos deixarmos sermos dominados pelos aliens nossa salvação? Ou deveríamos lutar? A resiliência da raça humana e sua luta pela liberdade e independência não abandona os roteiros de ficção, pois parecemos ainda querer acreditar em nossa capacidade de salvar nosso futuro. Essas inquietações, entretanto, demonstram as dúvidas frente a crises que parecem agravar-se com o passar do tempo, parecemos questionar inclusive nossa capacidade de resolvê-las sozinhos.

The Walking Dead, que retrata o mundo dos sobreviventes de um apocalipse zumbi, estreou em 2010, enquanto navegávamos as reticências de uma recessão econômica global. O programa ressoou com os espectadores: os zumbis não eram mais margens, mas massas normalizadas, familiares, como muitos amigos e familiares desocupados das demissões em massa, clamando por qualquer trabalho. Além disso, como os fãs atestarão, os zumbis são o menor problema quando você os mede contra a humanidade dos sobreviventes. Séries mais recentes seguiram o sucesso do seriado, como Z Nation (2014), que tem um enredo similar, iZombie (2015), que parte do presente, com o surgimento dos primeiros zumbis, para imaginar como será o futuro e quem irá dominá-lo, humanos ou mortos-vivos, e Fear the Walking Dead (2015), um spin-off de The Walking Dead que traz um olhar sobre o início do apocalipse zumbi e o colapso da sociedade.

A série True Blood foi ao ar em 2008 e imaginava um futuro no qual os vampiros se tornaram parte do cotidiano e os humanos buscavam uma forma de conviver pacificamente com eles. Ela evidenciou, contudo, conflitos sobre a capacidade dos seres humanos de administrar a sua existência. Seriam vampiros uma raça superior, que conseguiriam fazer um trabalho melhor em garantir a sobrevivência do planeta terra? A série Van Helsing (2016), mais recente, já propõe um cenário no qual os vampiros dominam o mundo e os humanos devem escolher entre lutar por sua sobrevivência ou se resignarem a viverem como escravos.

Além de apocalipses sobrenaturais, trazidos por aliens, zumbis e vampiros, as telas de televisão também trouxeram eventos de extinção da raça humana provocados pelo próprio homem, por um evento de impacto ou por vírus. Na série The 100 (2014), vemos os sobreviventes de um apocalipse nuclear lutando pela permanente existência da raça humana no espaço, ao mesmo tempo em que um grupo de jovens, que cresceu no espaço, retorna ao radioativo planeta terra, que havia sido dizimado décadas antes por uma guerra nuclear, para reaprender a sobreviver em solo firme.

O seriado Revolution (2012) retrata um mundo em que os seres humanos tiveram de reaprender a viver sem eletricidade, anos depois de um blackout mundial, e a constante busca pela capacidade de recuperar a energia elétrica e reorganizar a sociedade, que entrou em colapso quando todas as luzes se apagaram. The Last Ship (2014) narra o drama de uma tripulação de um navio norte-americano, que depois de meses em uma missão secreta sem contato com o mundo exterior, descobre que a sociedade que conheciam sucumbiu a um vírus mortal e sua única esperança de salvar a raça humana é encontrar uma cura.

Esses seriados são apenas alguns exemplos dentre vários que passaram a tomar conta da tela de televisão, mas demonstram a crescente popularidade 

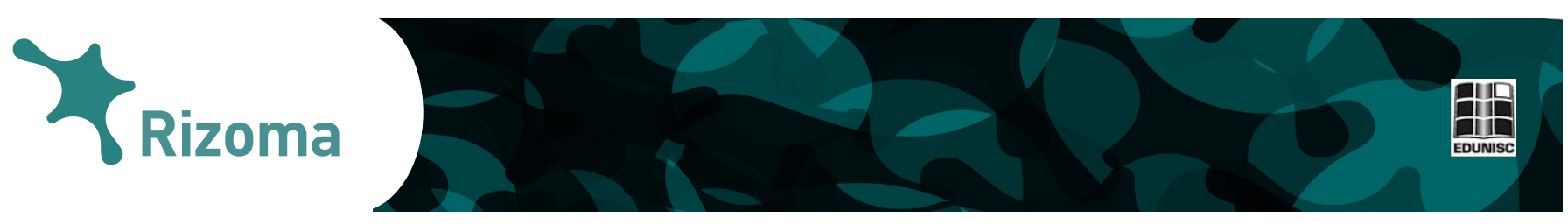

dos seriados de ficção científica e uma demanda por este tipo de história, que exprime anseios e angústias de novas gerações quanto ao seu futuro. Os personagens, mesmo em mundos fantásticos, tornam-se receptáculos de nossas próprias paixões, que podem ser tanto provocadas pela própria história que estamos acompanhando quanto serem exteriores a ela (ECO, 1994). As narrativas mostram-se capazes de auxiliar as pessoas a pensarem conflitos do mundo à sua volta e a compreenderem situações de seu dia a dia, encontrando na ficção respostas para questões que se apresentam em suas vidas.

\section{Mediações televisivas como portais para futuros imaginados}

Como a humanidade encontrará seu fim? É uma questão que tem tomado conta das telas de televisão. Há algo instigante sobre histórias distópicas - Nosso mundo está quebrado, e agora? O que acontece se nosso mundo for destruído e nós devemos começar de novo? Que tipo de sociedade construiríamos? É dramaticamente muito interessante e apela aos espectadores, que se encontram no cotidiano frente a estas questões.

Seriados e ficção científica têm um ponto de encontro na capacidade de relação que forma com o espectador ao produzirem uma resposta emocional à ficção - o futuro é sentindo, imaginado e considerado (LOMBARDO, 2006; JOST, 2012). O consumo televisivo é carregado de significado cultural, à medida que os espectadores se inserem em contextos sociais e atribuem uma valoração para os conteúdos que escolhem consumir (HERMAN, 2012).

Os futuros distópicos criados nas telas de televisão podem ser apenas ficcionais, mas as sociedades sombrias e opressivas, ilustrando os horrores possíveis de nosso futuro, dão vida à imaginação e trazem respostas para as inquietantes questões do que está por vir em um panorama de crises e desesperança. As ficções distópicas acabam refletindo invariavelmente as preocupações e os medos da cultura contemporânea, extrapolando os cenários do pior caso possível, seja como uma forma de escape ou de advertências para a mudança ou cautela social necessária.

Nos últimos anos, cresceram o número de obras de ficção que retratam futuros distópicos, sejam livros, filmes ou seriados. Os mais jovens, em particular, têm tido um fascínio por esse tipo de história, que está se tornando parte da consciência das novas gerações. Eles crescem em um contexto onde o fim do mundo e a extinção da raça humana fazem parte da conversa o tempo todo - as estatísticas de nosso planeta se aquecendo, o ambiente está mudando, os conflitos armados estão se multiplicando, os índices de desemprego crescem etc. Assim, torna-se uma inevitabilidade considerar essas questões viscerais e óbvias, que nos fazem discutir o futuro e como iremos sobreviver. É parte da vida cotidiana das gerações mais jovens, que de forma consciente ou não, perguntam-se como será seu futuro, em um momento em que parece mais fácil imaginar o fim do mundo do que imaginar, por exemplo, o fim do capitalismo e das redes de fast food. 

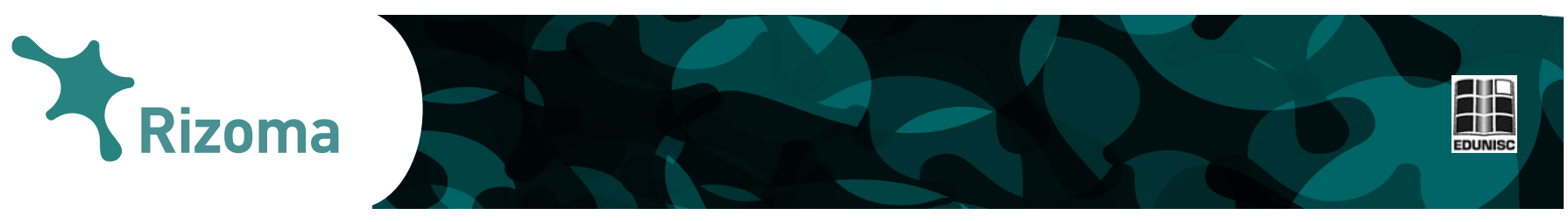

Os seriados de ficção que trazem guerras nucleares e vírus mortais parecem dolorosamente possíveis atualmente, e mesmo aqueles que trazem aliens, zumbis e vampiros como nosso futuro, tornam-se populares. Esses nos permitem refletir sobre as duras realidades do nosso momento presente, em condições difíceis de enfrentar diretamente, tornando a ficção uma forma de mediação confortável e conveniente. Mesmo que aparentemente configurado no futuro, o modo pós-apocalíptico pode funcionar como uma janela e crítica do presente, que nos permite lidar com a nossa atual apatia e inatividade diante de um futuro parco.

Há um conforto peculiar em consumir histórias distópicas. São lembretes, apesar de refletir um presente horrível, de que nunca é tarde demais para nós, que não estamos tão longe e que podemos reverter a maquinaria que faz nossos pesadelos reais. Talvez sejam uma espécie de ladainha para a sobrevivência, que a humanidade continuará apesar dos nossos melhores esforços para nos destruir.

Todo mundo quer saber o que acontece no futuro. Nós já conhecemos o passado; seriados sobre o passado são interessantes, mas os programas sobre o futuro são realmente intrigantes porque queremos saber o que acontecerá. É por isso que as histórias distópicas apelam para os espectadores. A ficção permite que nossas imaginações ganhem vida nas telas e nos tragam o conforto de podermos viver, pensar e enfrentar, através das narrativas de diferentes personagens, nossas ansiedades, angústias e medos em relação ao futuro.

\section{Referências}

AUMONT, Jacques. A Estética do Filme. São Paulo: Papirus, 2002.

BALL, A. (Produtor). True Blood. [Série de Televisão]. 2008. Estados Unidos: Home Box Office (HBO).

CARLOS, Cassio Starling. Em tempo real: Lost, 24 horas, Sex and the City e o impacto das novas séries de TV. São Paulo: Alameda, 2006.

CONDAL, R. J.; CUSE, C. (Produtores). Colony. [Série de Televisão]. 2016. Estados Unidos: Legendary Television; Universal Cable Productions.

DARAPONT, F. (Produtores). The Walking Dead. [Série de Televisão]. 2010. Estados Unidos: AMC Studios.

ECO, Umberto. Seis passeios pelos bosques da ficção. São Paulo:

Companhia das Letras, 1994.

ERICKSON, D.; KIRKMAN, E. (Produtores). Fear the Walking Dead. [Série de Televisão]. 2015. Estados Unidos: AMC Studios.

FRANKLIN, Bruce H. Look Where We're Going: Visions of the Future in 

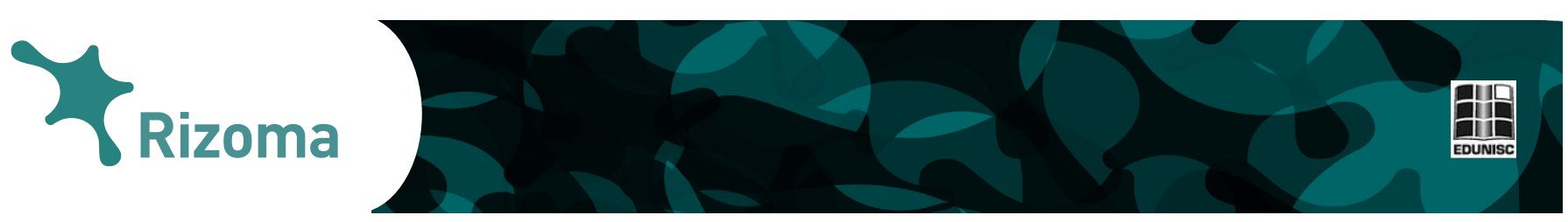

Science-Fiction Films, 1970-82. Science Fiction Studies, Greencastle, v. 10, n. 1, pp. 70-80, 1983. Disponível em: <http://www.jstor.org/stable/4239529> Acesso em: 21 mai. 2017.

HELFAND, Jessica. Screen: essays on graphic design, new media and virtual culture. Nova York: Princeton Architectural Press, 2001.

HERMAN, David. Toward a transmedial narratology. In: Ryan, MarieLaure. Narrative Across Media. The languages of storytelling. Nebraska: University of Nebraska, pp. 50-75, 2012.

JOST, François. Do que as séries americanas são sintoma? São Paulo: Sulina, 2012.

KRANE, S.; STEINBERG, H. (Produtores). The Last Ship. [Série de Televisão]. 2014. Estados Unidos: TNT Original Productions.

KRIPKE, Eric. (Produtor). Revolution. [Série de Televisão]. 2012. Estados Unidos: Warner Bros Television.

LOMBARD, Thomas. Contemporary Futurist Thought: Science Fiction, Future Studies, and Theories and Visions of the Future in the Last Century. Bloomintong: AuthorHouse, 2006.

REGINA, C.; NANKIN, M.; MARCH, D.; LABUTE, N.; BARRY, S.; OAKES, C.; FRISLEV, M. (Produtores). Van Helsing. [Série de Televisão]. 2016. Estados Unidos: Echo Lake Entretainment; Nomadic Pictures.

ROSENBAUM, S.; SIMONEAU, Y. PETERS, S.; PEARLMAN, S.; HALL, J. (Produtores). V. [Série de Televisão]. 2008. Estados Unidos: Warner Bros Television.

ROTHENBERG, Jason. (Produtores). The 100. [Série de Televisão]. 2014. Estados Unidos: Warner Bros Television.

SPIELBERG, Steven. (Produtor). Falling Skies. [Série de Televisão]. 2011. Estados Unidos: TNT Original Productions.

STABLEFORD, Brian. The Third Generation of Genre Science Fiction. Science Fiction Studies, Greencastle, v. 23, n. 3, pp. 321-33, 1996. Disponível em: <http://www.jstor.org/stable/4240537> Acesso em: 20 mai. 2017. 